Research ethics

\section{The scandal of unfair behaviour of senior faculty}

\section{E J Wagena}

\section{Misappropriation of authorship needs to be abolished}

A cademia bases reputation and standing on the number of published articles. As a result, the abilities and potential of (junior) researchers are also being judged by the number of (scientific) articles they write, as well as on the impact factor of the journals in which their articles are being published. In itself this is not a problem, although one could of course question the assumption that the quantity of the output (and the impact factor of journals) reflects the competence of individual researchers. As Altman has stated: "The length of a list of publications is a dubious indicator of ability to do good research."1 However, if senior faculty decide that the career progress of junior researchers in academia should be based on these criteria, academic medicine is bound to fail in fulfilling (one of) its role(s), namely maximising the quality of medical research and doing research for the right reasons. And to some extent it already has. ${ }^{1}$

Used appropriately, authorship establishes accountability, responsibility, and credit for scientific information reported in biomedical publications. ${ }^{2}$ Misappropriation of authorship therefore undermines the integrity of the authorship system. An increasing number of senior researchers, however, seem to place more value on the number of publications in which their name appears in the byline, than on their actual contribution.

The integrity of publications depends above all on the professional commitment to truth and honesty of senior researchers, since it seems unlikely that junior researchers can have much influence on authorship decisions. Apparently, journal editors have also recognised this problem: the requirements laid down by the International Committee of Medical Journal Editors (ICMJE) include ethical principles related to publication in biomedical journals. ${ }^{3}$ Why would we need guidelines for authorship if senior faculty behaved fairly? However, even the ICMJE's Uniform Requirements for Manuscripts Submitted to Biomedical Journals (which have been adopted by most biomedical journals) are being disregarded by (senior) authors, ${ }^{4}$ and a variety of misuses of the current authorship system have been described (see Flanagin et $a l^{2}$ and Mowatt et $a l^{5}$ ). Senior researchers seem to go to considerable lengths to increase the list of publications on their curriculum vitae, and in many cases at the expense of junior researchers, since junior researchers are responsible for a major part of the scientific output of senior researchers. For career reasons (that is, to be able to show a longer list of publications), they even seem to be willing to conduct poor medical research. ${ }^{1}$

Dishonest and unfair behaviour of senior faculty regarding authorship has serious consequences for the development of junior researchers into competent senior faculty with vision. By using the number of publications as a criterion for career progression, junior researchers are being given the impression that academia is not about maximising the quality of medical research and doing research for the right reasons. Instead, senior faculty are setting a bad example by showing how to work your way onto the byline of articles without contributing sufficiently. In an atmosphere in which the number of published articles establishes reputation and standing, it is difficult for junior faculty to progress in their career in academia and at the same time maintain their integrity. Most do not hold permanent appointments and as a result may be afraid to confront their supervisors (often full professors) over authorship decisions, which may make it hard for them to get an extension of their contract. I can testify that life can be made very difficult for a junior researcher who raises questions about whether a more senior colleague demanding coauthorship has made the substantive contribution to a project upon which authorship would be justified. Journal editors can help more junior staff faced with this situation by requiring explicit, signed information describing the contribution of each coauthor. But academia itself must create mechanisms for ensuring that gift authorship among senior academics is outlawed.

The British Medical Journal and a range of partners, including other journals published by the BMJ Publishing Group have initiated a project to bring people together to debate whether the existing structure of academic medicine is still fundamentally sound and, if not, to propose alternatives to it. ${ }^{6}$ Polishing the tarnished image of academic medicine $^{7}$ is certainly not the answer to the problems it faces. A broad international debate is needed in which solutions to the inadequate leadership of senior faculty and deficient mentoring for aspiring academics are discussed and formulated into concrete proposals for action. For the campaign to be a success, the biggest challenge, however, will not be to start this debate, especially since major medical journals are backing it, but to call senior faculty to account for their unfair behaviour. To achieve this, the leaders of medical academia need to recognise the extent of the problem and realise that they can make a difference. Only then will the project really solve the problem described here.

J Med Ethics 2005;31:308.

doi: 10.1136/jme.2004.009308

Correspondence to: E J Wagena, Pulmonary Rehabilitation Centre Hornerheide, PO Box 4080, 6080 AB Haelen, the Netherlands; edwinwagena@proteion.nl

\section{REFERENCES}

1 Altman DG. The scandal of poor medical research. BMJ 1994;308:283-4.

2 Flanagin A, Carey LA, Fontanarosa PB, et al. Prevalence of articles with honorary authors and ghost authors in peer-reviewed medical journals. JAMA 1998;280:222-4.

3 International Committee of Medical Journal Editors. Uniform Requirements for Manuscripts Submitted to Biomedical Journals. Available at www.icmie.org (accessed 12 January 2004).

4 Bhopal R, Rankin J, McColl E, et al. The vexed question of authorship: views of the researchers in British medical faculty. BMJ 1997;314:1009-12.

5 Mowatt G, Shirran L, Grimshaw JM, et al. Prevalence of honorary and ghost authorship in Cochrane reviews. JAMA 2002;287:2769-71.

6 Tugwell P. Compaign to revitalise academic medicine kicks off. BMJ 2004;328:597.

7 Clark J. Polishing the tarnished image of academic medicine. BMJ 2004;328:604. 